\title{
Chemotherapy in Lung Cancer with Hepatic and Renal Impairment
}

\author{
Aida Hastuti ${ }^{1 *}$, Erna Kusumawardhani ${ }^{2}$, Haryati ${ }^{2}$ \\ ${ }^{1}$ Department Internal Medicine Faculty of Medicine, \\ Lambung Mangkurat University, Ulin Hospital, Banjarmasin \\ ${ }^{2}$ Department Pulmonology and Respiratory Medicine Faculty of Medicine, \\ Lambung Mangkurat University, Ulin Hospital, Banjarmasin
}

\begin{abstract}
Corresponding Author:
Aida Hastuti| Department of Internal Medicine, Faculty of Medicine, Lambung Mangkurat University, Ulin Hospital, Banjarmasin | aidahastuti@gmail.com

Submitted: January $18^{\text {th }}, 2022$

Accepted: February $1^{\text {st }}, 2022$

Published: February $28^{\text {th }}, 2022$
\end{abstract}

Respir Sci. 2022; 2(2): 110-123

https://doi.org/10.36497/respirsci.v2i2.42

\begin{abstract}
Chemotherapy is one of the therapeutic modalities for lung cancer. Chemotherapy with anticancer drugs has a narrow therapeutic index and pharmacokinetic variability between individuals. The administration of anticancer drugs should consider many factors that may affect the pharmacokinetics of the drug, such as hepatic and renal function. In lung cancer patients who have hepatic and renal impairment, an adjusted dose of anticancer drug is needed to achieve levels of drug exposure similar to patients who have normal organ function and avoid toxicity. Renal function is calculated by the glomerular filtration rate or creatinine clearance. Assessment of hepatic function can be taken from Child Pugh's score or from bilirubin and aminotransferase enzyme data in patients. In addition, hepatitis screening is also required. The results of the assessment will determine the adjustment dose recommendation for anticancer drugs.
\end{abstract}

Keywords: chemotherapy, lung cancer, hepatic impairment, renal impairment

\section{INTRODUCTION}

Cancer is a significant disease problem globally and affects 100 million individuals worldwide. ${ }^{1}$ Globally, cancer is the leading cause of death. Globocan data states that in 2020 there were 19.3 million new cases with a death rate of 10.0 million deaths. ${ }^{2,3}$ The incidence of cancer in Indonesia (136.2/100,000 population) is ranked 8th in Southeast Asia, while in the Asian continent, it is $23^{\text {rd }}$. The highest incidence of cancer in Indonesia for men is lung cancer which is $19.4 / 100,000$ population (average death rate is $10.9 / 100,000$ population), followed by liver cancer at $12.4 / 100,000$ population (7.6/100,000 population average death). In women, the highest incidence of cancer is breast cancer, $42.1 / 100,000$ population (average death is $17 / 100,000$ population), followed by cervical cancer at 23.4 per 100,000 population with an average death rate of 13.9 per 100,000 population. ${ }^{3}$ 
Lung cancer is one of the most deadly and common types of cancer globally. Lung cancer is the leading cause of cancer worldwide, accounting for up to $13 \%$ of all cancer diagnoses. In 2018, more than 1.7 million people died from lung cancer. Based on the origin of the cells, about $80-85 \%$ of lung cancers are non-small cell carcinomas (NSCLC), which are further divided into lung adenocarcinomas, squamous cell carcinomas, and large cell carcinomas based on histology. ${ }^{4,5}$

One of the therapeutic modalities in cancer patients is the administration of chemotherapy or anticancer drugs. However, anticancer drugs have a characteristic narrow therapeutic index and sizeable pharmacokinetic variability between individuals. ${ }^{1}$ In general, anticancer drugs are administered at their maximum tolerated dose. Therefore, understanding the effects of pharmacokinetic changes in certain anticancer drugs is essential to determining the appropriate initial amount to maximize efficacy and avoid toxicity. ${ }^{6}$

The administration of anti-cancer drugs must consider other factors that may affect the pharmacokinetics of the drug, such as liver and kidney function ${ }^{6}$ as well as excretion of drugs. ${ }^{1}$ Renal and hepatic impairment are common disorders in the general population, including cancer patients. ${ }^{6}$

Renal function is an essential consideration in managing patients with advanced cancer. There is a reciprocal relationship between cancer and the kidney. Chronic kidney disease may increase the risk of developing cancer, and patients with cancer often develop renal impairment due to age, disease-related factors, and nephrotoxic treatment. ${ }^{7}$ Previous studies have shown that approximately $55 \%$ of patients with cancer have an estimated glomerular filtration rate of less than $90 \mathrm{~mL} / \mathrm{min}$ and about $15 \%$ of patients have an estimated glomerular filtration rate of less than $60 \mathrm{~mL} / \mathrm{min}^{6}$

For liver disorders, specific prevalence data for patients with cancer has not yet been found. Liver disorders can reduce metabolic capacity, bile outflow, hepatic blood flow, and plasma protein levels, leading to increased exposure to the parent compound. Therefore, understanding drug metabolism pathways and pharmacokinetic changes is critical in making dosing decisions. ${ }^{6}$ Hepatitis B virus (HBV) or hepatitis $\mathrm{C}$ virus (HCV) infection is associated with significant morbidity and mortality in patients with cancer. According to research, hepatitis $B$ infection is related with a poor outcome in chronic kidney disease (CKD) patients. ${ }^{8,9}$

\section{PHARMACOKINETICS OF ANTICANCER DRUGS}

Pharmacokinetics can be defined as the science of absorption, distribution, metabolism, and excretion. In simple terms, pharmacokinetics is defined as what the body does to the drug, which is depicted in Figure 1. ${ }^{10}$ 


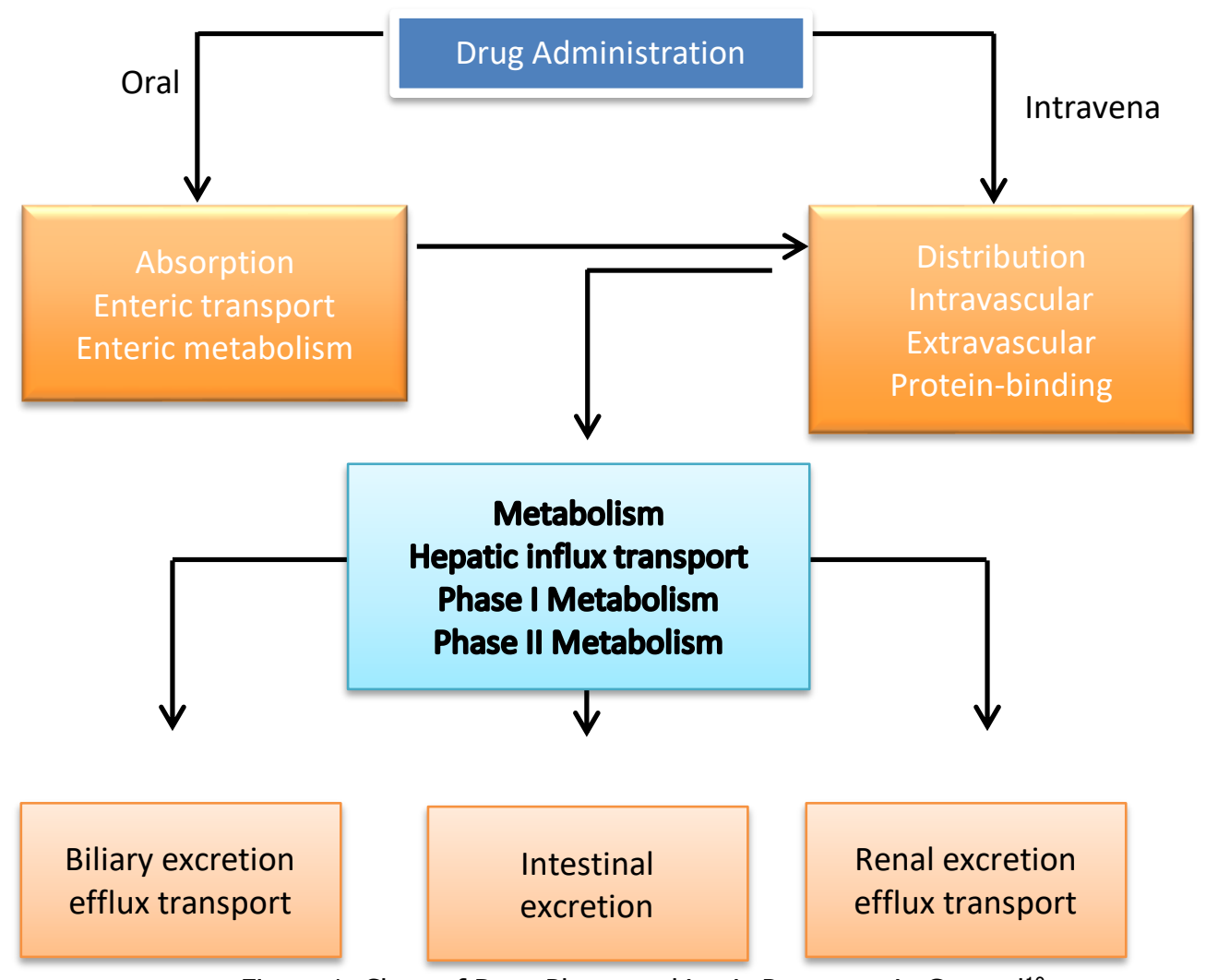

Figure 1. Chart of Drug Pharmacokinetic Processes in General ${ }^{10}$

\section{Drug Absorption}

Most anticancer drugs are given intravenously or orally. Intravenous drug administration is the most direct route and results in rapid and complete bioavailability. In contrast, the bioavailability of oral drugs still depends on absorption barriers. As a result, oral medications typically have much greater pharmacokinetic variability than intravenous drugs. Intestinal absorption is regulated by absorption surface area, intestinal transit time, blood flow to the absorption site, and gastric and intestinal $\mathrm{pH}$. It is also influenced by genetic differences in the transport system and drug metabolism in the gut. ${ }^{10}$

There is a drug-efflux pump in the intestinal transport system, namely $\mathrm{P}$ glycoprotein (P-gp) encoded by $A B C B 1$. The presence of polymorphisms in $A B C B 1$ causes variations in P-gp activity, which causes variations in drug pharmacokinetics. ${ }^{10}$

P-gp is expressed in the intestinal epithelium and actively removes drugs from tumor cells, thereby inhibiting the absorption of oral anticancer drugs. Intestinal drug metabolism is affected by CYP3A, a subclass of cytochrome P450 enzymes. The cytochrome P450 enzyme is an intracellular heme-containing oxidizing enzyme responsible for the first phase of the metabolism of many drugs. CYP3A itself is located in the liver and intestines. In the gut, CYP3A4 is the predominant P450 enzyme (70\%), located on the crest of mature enterocytes and adjacent to the junction of the intestinal microvilli. CYP3A4 polymorphisms may influence the pharmacokinetic differences of a drug. ${ }^{10}$ 


\section{Drug Distribution}

After absorption or intravenous administration, the drug is distributed from the intravascular space to its target in the extravascular space. Most drugs are bound to plasma proteins such as albumin and glycoprotein acids. The amount of drug moving into the extravascular space depends on how much protein-bound and free drug there is, with only the nonprotein-bound or "free" drug being pharmacologically active. Protein binding is usually a saturated process, so differences in plasma protein levels between patients will result in differences in drug distribution. ${ }^{10}$

\section{Drug Metabolism}

Metabolism is the most important and complex step in drug disposition and can be a significant source of pharmacokinetic variability. A transporter protein, namely organic anion-transporting polypeptide (OATP), carries drugs and their metabolites from the blood to hepatocytes. Once in the liver, anticancer drugs undergo phase I and phase II reactions. ${ }^{10}$

Phase I reactions change the medicine to be more polar and easily excreted to become inactive, more active, or less active. In contrast, the phase II reaction is conjugation with endogenous substrates such as glucuronic acid, sulfuric acid, acetic acid, or amino acids. Consequently, the drug almost always becomes inactive. ${ }^{10}$

In the most critical phase I metabolic reactions, the primary process is oxidation, catalyzed by the enzyme cytochrome P-450
(CYP450) monooxygenase in the endoplasmic reticulum (microsome) of the liver. The majority(50\%) of medicines are metabolized by CYP3A4, a cytochrome P450 enzyme located largely in the liver and intestines. Therefore, the CYP3A4 enzyme plays a critical role in the metabolism and first-pass elimination of various drugs. ${ }^{10}$

Phase II reactions conjugate phase I products to form derivatives that are usually inactive for renal and biliary elimination. The most critical process is glucuronidation via the enzyme UDPglucuronyl-transferase (UGT), which mainly occurs in liver microsomes and extrahepatic tissues (small intestine, kidney, lung, skin). Other conjugation reactions (acetylation, sulfation, conjugation with glutathione) occur in the cytosol. ${ }^{10}$

\section{Drug Excretion}

The main routes of drug excretion are through the bile ducts and kidneys. Mechanical obstruction of the biliary tract due to hepatic metastases may impair biliary excretion, and decreased serum albumin associated with malnutrition has been associated with decreased biliary excretion of anticancer drugs. Some anticancer drugs, such as platinum compounds, are eliminated mainly through the kidneys. The presence of renal insufficiency characterized by a decrease in the glomerular filtration rate (GFR) can reduce drug clearance. GFR can decrease with age. ${ }^{10}$ 


\section{ACTION MECHANISM OF ANTI- CANCER DRUGS}

The stages of the cell cycle are divided into two main phases (interphase and mitosis). In the interphase, cell growth and DNA copying occur. This phase begins with the G1, where the cell grows enlarged, organelles are copied, and molecular walls are formed. The $S$ phase is when the cell synthesizes a copy of DNA in its nucleus. Cells also duplicate microtubule-organizing structures called centrosomes. Centrosomes help separate DNA during the later $M$ phase. The $G 2$ phase is characterized by an increasing number of cells. They also form proteins and organelles in this phase. Once all is well, the mitosis phase is ready to begin. The mitosis phase of the cell divides the DNA and cytoplasm that have previously been copied into two parts and the cell itself divides. In this mitosis phase, there are four stages that occur. The stage begins with prophase, metaphase, anaphase, and ends with telophase. ${ }^{11}$

Anti-cancer drugs interact with DNA in various ways. The formation of complexes between DNA and drugs will lead to changes in the thermodynamic stability and functional properties of DNA. ${ }^{11}$ Pharmacodynamics of anti-cancer medications depends on how the drug itself works. Some anti-cancer drugs act in nonspesific phases. And some drugs act on certain specific phases of the cell cycle. For example, antimetabolites are mainly active during the $\mathrm{G} 1$ and $\mathrm{S}$ phases, and topoisomerase inhibitors target the $\mathrm{S}$ phase, whereas spindle toxins are only involved in mitotic cells. As shown in Figure 2, there are four classes of anti-cancer drugs commonly used for the treatment of lung cancer, which are as follows: ${ }^{12}$

1. Alkylation drugs, including cisplatin and carboplatin, directly damage DNA by interrupting replication and transcription.

2. Antimetabolites (pemetrexed, gemcitabine) interrupt nucleic acid synthesis.

3. Topoisomerase inhibitors are critical enzymes that loosen DNA supercoiling during replication and transcription, including topoisomerase I (topotecan) and topoisomerase II (etoposide).

4. Spindle toxins that interfere with the polymerization or depolymerization of mitotic spindle microtubules, including vinorelbine, paclitaxel, and docetaxel.

Chemotherapy can be used as a neoadjuvant or postoperative adjuvant in early-stage lung cancer. Adjuvant therapy can be given to NSCLC stages IIA, IIB, and IIIA. If the patient's overall appearance is favorable (Karnofsky >60\%; WHO0-2), chemotherapy can be given in the advanced stage of NSCLC. However, the most significant benefit of chemotherapy is as palliative therapy in patients with advanced stages. ${ }^{5}$

The first line is given to patients who have never received chemotherapy treatment for lung cancer. This group consists of platinum-based and nonplatinum-based chemotherapy (new generation drugs). 


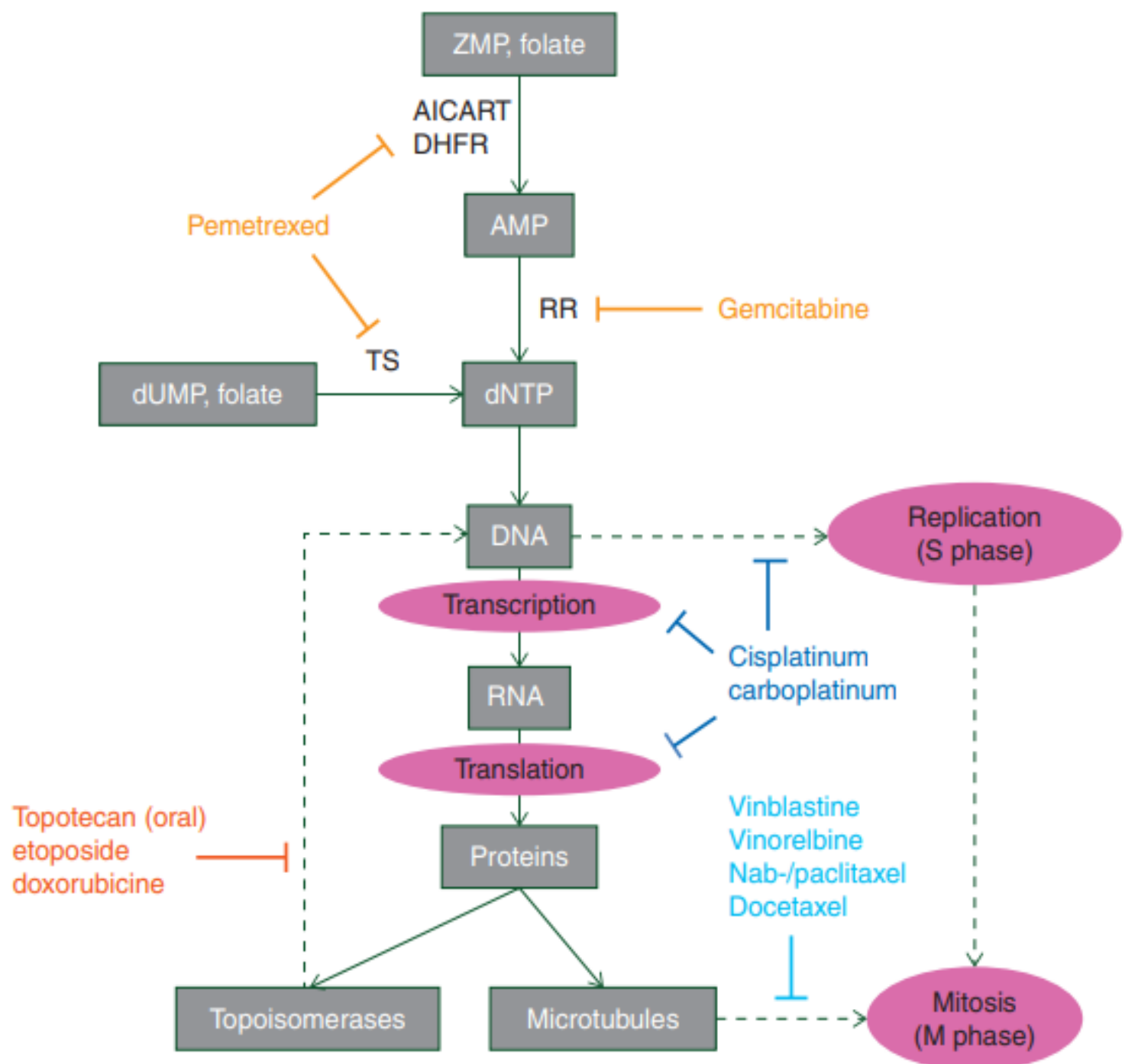

Figure 2. Mechanism of Action of Anti-cancer Drugs on Lung Cancer ${ }^{12}$

The primary choice for platinumbased medicines is cisplatin, with carboplatin as the other option. The nonplatinum-based first-line chemotherapy drugs that can be given are etoposide, gemcitabine, paclitaxel, and vinorelbine. The combination of cisplatin with gemcitabine provides the highest survival rate, but the best response is to the cisplatin regimen with paclitaxel.

Second-line chemotherapy was given to patients who received first-line chemotherapy but did not respond after 2 cycles or became more progressive after chemotherapy was completed. Second-line chemotherapy drugs are docetaxel and pemetrexed. In addition, a combination of two non-platinum-based drugs may also be given. Third-line chemotherapy and beyond is highly dependent on the history of previous treatment. ${ }^{5,13}$

\section{KIDNEY DISORDER ASSESSMENT}

Renal function is usually expressed as an estimate of the glomerular filtration rate based on creatinine clearance. Measuring the glomerular filtration rate with the 
isotopic marker Cr-EDTA is considered the gold standard in patients with cancer. However, this approach is not routinely used in practice because of its high cost. ${ }^{6}$ Different methods for measuring glomerular filtration rate, e.g., 24-hour urine test or calculations using the Martin, Wright formula, Cockcroft and Gault formula, MDRD, or Chronic Kidney Disease formula Epidemiology Collaboration [CKDEPI]). ${ }^{7}$ Currently, the recommended guideline is the use of the CKD-EPI formula for estimating the glomerular filtration rate. ${ }^{6,8}$ The differences between several methods of measuring glomerular filtration rate can be seen in Table $1 .^{14}$

After estimation of renal function is performed, Kidney Disease Outcomes Quality Initiative (KDOQI) and Kidney Disease: Improving Global Outcomes
(KDIGO) have defined the stratification of the degree of kidney disorders as in Table 2. This international definition should also be used in patients with cancer. ${ }^{15-17}$

Renal impairment may affect 1 or more of the 4 pharmacokinetic phases (absorption, distribution, metabolism, and elimination/excretion). Reduced renal function can reduce the excretion of metabolites from anticancer drugs because anticancer drugs are eliminated either wholly or partially in the kidney. This decreased excretion can lead to drug accumulation and increased exposure to toxicity. ${ }^{6}$ This disorder can cause modifications in the pharmacokinetic profile of the drug administered so that an adjustment in the dose of anticancer drugs is required to avoid drug accumulation and reduce side effects. ${ }^{6,15}$

Table 1. Several Methods of Measuring Glomerular Filtration Rate

\begin{tabular}{|c|c|}
\hline Formula & Formulation \\
\hline \multicolumn{2}{|l|}{ Creatinin clearance } \\
\hline Cockcroft-Gault, ml/minute & $(140$-age $) \times \mathrm{BB} \times(1-0.15 \times$ sex $) / \mathrm{Cr} \times 0.814$ \\
\hline Jelliffe, $\mathrm{ml} /$ minute & $(98-0.8 \times($ Age-20) $) \times(1-0.1 \times$ sex $) \times \mathrm{BSA} / 1.73) / \mathrm{Cr} \times 0.0113$ \\
\hline Wright, $\mathrm{ml} /$ minute & $(6580-38.8 x$ age $)$ xBSAx $(1-0.168 x$ sex $) / C r$ \\
\hline \multicolumn{2}{|c|}{ Calculation of eGFR } \\
\hline Modification of Diet in Renal Disease (MDRD) & $\begin{array}{l}\text { GFR }=186 \times \text { SCr-1.154x Age- } 0.203 \times 1.212 \text { (if the patient is black) } \\
\times 0.742 \text { (if female) }\end{array}$ \\
\hline CKD-EPI creatinine & $\begin{array}{l}\mathrm{SCr} 0.7 \text { (female) and SCr } 0.9 \text { (male) } \\
144 \times(\mathrm{SCr} / 0.7)-0.329 \times 0.993 a g e \times(1.159 \text { if black race) (if female) } \\
141 \times(\mathrm{SCr} / 0.7)-0.411 \times 0.993 \text { age } \times(1.159 \text { if black race) (if male) } \\
\mathrm{SCr} 0.7 \text { (female) and } \mathrm{SCr} 0.9 \text { (male) } \\
144 \times(\mathrm{SCr} / 0.7)-1.209 \times 0.993 a g e \times(1.159 \text { if black race) (if female) } \\
141 \times(\mathrm{SCr} / 0.7)-1.209 \times 0.993 \text { age } \times(1.159 \text { if black race) (if male) }\end{array}$ \\
\hline CKD-EPI Cystatin C & $\begin{array}{l}\text { For all Scys grades } 0.8 \text { or } 0.8 \\
133 \times(\text { Scys/0.08)-0.499x0.996age } \times 0.932 \text { (if female) } \\
133 \times(\text { Scys/0.08)-0.499x0.996age } \times 1.0 \text { (if male) }\end{array}$ \\
\hline \multicolumn{2}{|l|}{ Cancer-specificGFR equations } \\
\hline Calvert formula & Dosage $(\mathrm{mg})=\mathrm{AUC} \times(\mathrm{GFR}+25)$ \\
\hline Martin formula & $163 \times$ ABW $(1-0.00496 \times$ age $) \times(1-0.252 x$ sex $)$ \\
\hline
\end{tabular}


Table 2. Stratification of the degree of renal impairment based on KDOQI and KDIGO ${ }^{16}$

\begin{tabular}{clc}
\hline \multicolumn{1}{c}{ Stadium } & \multicolumn{1}{c}{ Description } & GFR \\
\hline $\begin{array}{c}\text { Patients with an } \\
\text { increased risk }\end{array}$ & $\begin{array}{l}\text { Risk factors for kidney disease (such as diabetes, } \\
\text { hypertension, family history, old age, etc.) }\end{array}$ & Over 90 \\
1 & Renal impairment and normal GFR & Over 90 \\
2 & Renal impairment and mild decrease in GFR & $60-89$ \\
3 & Moderate decline in GFR & $30-59$ \\
4 & The GFR weight loss & $15-29$ \\
5 & Kidney failure (dialysis or need a kidney transplant) & $<15$ \\
\hline
\end{tabular}
Note: Signs of kidney disorders: proteinuria, hematuria, etc. GFR: glomerular filtration rate

In patients with renal impairment, the dose reduction is expected to be directly proportional to the percentage decrease in the glomerular filtration rate. For the most part, anticancer drugs undergo biotransformation in the liver, where more and more water-soluble metabolites can be excreted via the kidney, where the required dose adjustment is more complex to predict. Anticancer drugs with a more comprehensive therapeutic index or large inter-individual variability may not directly require dose adjustment. Patients should also receive adequate hydration and careful monitoring of decreased renal function. ${ }^{6,7}$

There are three methods to adjust the dose according to the degree of renal function: ${ }^{18}$

1. Reducing the unit dose without modifying the dosing interval

2. Increasing the dosing interval without lowering the unit dose

3. Reducing the unit dose and increasing the dosing interval

In patients with renal impairment undergoing hemodialysis, information about the effect of hemodialysis on the pharmacokinetics of anticancer drugs is usually only found in case reports or small case series. Drug clearance in patients undergoing hemodialysis is determined by drug characteristics (e.g., protein-bound fraction, molecular weight, and volume of distribution), dialysis characteristics (e.g., pore size and flow rate), and patient characteristics (e.g., albumin level and residual renal function). For anticancer drugs that are excreted via the kidneys, dose adjustment is often necessary for patients undergoing hemodialysis. ${ }^{19}$

\section{LIVER DISORDER ASSESSMENT}

Liver metabolism plays a very important part in the pharmacokinetics of many chemotherapeutic drugs, especially their activation, degradation, and excretion. ${ }^{9}$ For liver function, the FDA and EMA recommend using the Child-Pugh scoring system to assess the effects of hepatic impairment. The Child-Pugh score consists of bilirubin, albumin, and prothrombin levels along with the presence or absence of encephalopathy and ascites, as shown in Table 3.

Initially, the Child-Pugh score was only developed to predict operative mortality in patients with liver cirrhosis. However, the Child-Pugh score is often used as a scale to assess liver disorders. 6,20 
Table 3. Assessment of Child Pugh scores based on clinical and laboratory criteria ${ }^{6}$

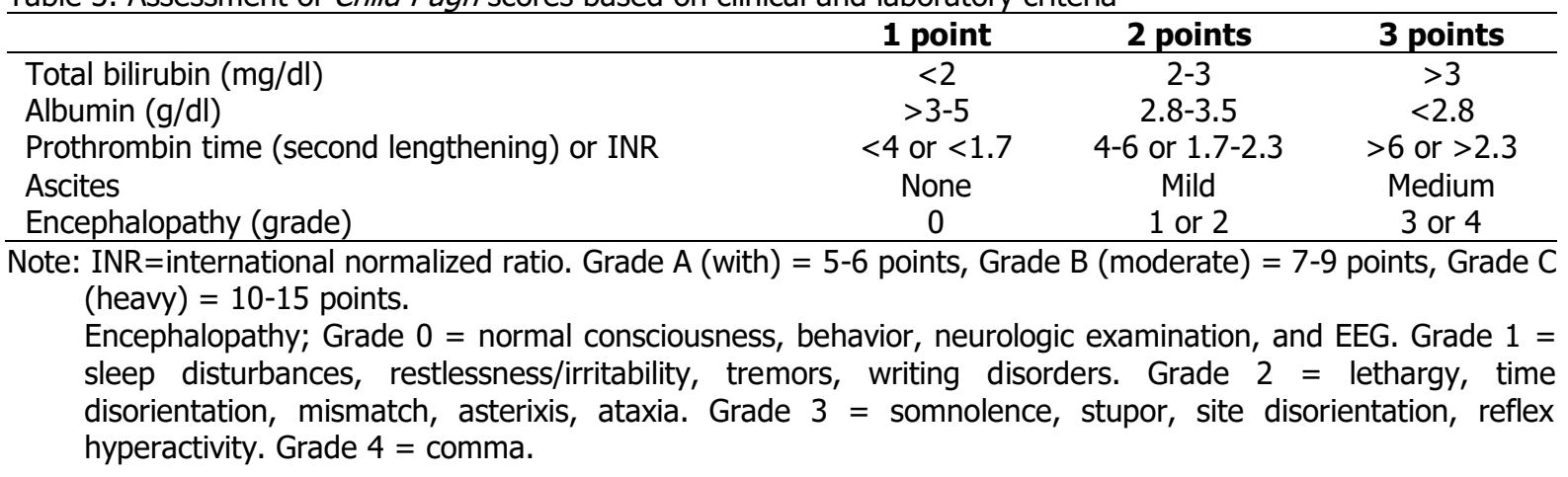

The FDA and EMA guidelines note the importance of verifying that those changes in the Child-Pugh component result from liver disease and are not caused by other underlying diseases such as cancer. The National Cancer Institute Organ Dysfunction Working Group recommends rating liver dysfunction as mild, moderate, or severe based on total bilirubin and transaminase concentrations, with bilirubin contributing most to metabolic capacity. 6,20

The liver is the main organ for drug metabolism and excretion for most anticancer drugs. The liver is the main organ that functions for drug metabolism and excretion, most of which are anti-cancer drugs. Liver function impairment is most common in patients with cancer, i.e., disorders caused by liver metastases. However, it could also be due to other factors such as hepatotoxicity from previous cancer treatments, cirrhosis, or hepatitis.

The impact of liver dysfunction on drug disposition is related to the type and severity of hepatic impairment as well as the physicochemical and pharmacokinetic characteristics of the drug. ${ }^{20}$ Biotransformation of drugs in the liver is very important for detoxifying active compounds and toxic metabolites and activating prodrugs. Therefore, reduced metabolic capacity can have profound effects on anticancer drug exposure. ${ }^{6}$ The less active metabolites are formed, the less effective therapy is in the patient. Reduced metabolic capacity may occur as a direct result of functional hepatocyte loss or an indirect result of the altered activity of drug-metabolizing and drug-transporting enzymes. ${ }^{9,20}$

Inhibited cytochrome P450 CYP3A4 activity has been reported in patients with cancer with an acute-phase inflammatory response. However, currently, liver serum biochemical tests do not provide an adequate assessment of the liver's metabolic capacity. ${ }^{21}$

Apart from the consequences of altered metabolic capacity, liver metastases and causes other than malignancy may also interfere with liver biochemical tests. In addition to decreased metabolic capacity, some changes in bile excretion, hepatic blood flow, and plasma protein binding may also occur in patients with hepatic impairment. Obstruction of biliary excretion can lead to drug accumulation, leading to hepatocellular damage. ${ }^{6}$ 
Before starting treatment, HBsAg and anti-hepatitis B screening should be performed in patients at high risk for HBV infection (i.e., patients from areas of high HBV endemicity, with a history of intravenous drug abuse, on hemodialysis, or who are HIV-positive, or homosexual men). Hepatitis $B$ reactivation, defined as the development of hepatitis with elevated serum HBV DNA levels, is a complication in cancer patients undergoing cytotoxic chemotherapy and can lead to death. This risk was related to the status of HBV infection before chemotherapy and the degree of immunosuppression during chemotherapy. Antivirals are given 1-2 weeks before chemotherapy and are maintained until the immune condition improves, although it is difficult to define. ${ }^{22}$ In cases of high risk of reactivation, prophylactic lamivudine significantly reduces the prevalence of $\mathrm{HBV}$ reactivation in patients with hematological malignancies and patients with solid tumors. 8,9,23

$\mathrm{HCV}$ infection is more common than HBV infection in cancer patients. Therefore, if an anti-HCV screening is positive, a qualitative HCV RNA PCR examination will be continued. ${ }^{23}$ Patients with positive antiHCV will then be tested for HCV RNA PCR. In addition, it is necessary to carefully monitor HCV viral load and alanine transaminase (ALT) levels during and after chemotherapy. 8 There is no established prophylaxis for HCV infection. However, in chronic hepatitis $\mathrm{C}$, alpha interferon and ribavirin can be given, which is said to be effective. ${ }^{8,9}$

\section{CHEMOTHERAPY DOSAGE ADJUSTMENT IN LIVER AND KIDNEY DISORDERS}

Based on the liver and kidney function data, it is possible to recommend the dose to be given, namely the full dose recommendation, percent recommendation, the specific recommendation in milligrams per square meter, or recommendation to postpone administration. Adjustment of the dose of anti-cancer drugs for chemotherapy in lung cancer can be seen in Table $4 .^{8}$

In lung cancer, anti-cancer drugs that require dose adjustment in renal impairment are cisplatin, carboplatin, etoposide, and pemetrexed. Cisplatin is not recommended in renal impairment with a GFR <60. Pemetrexed is also not recommended if the GFR is $<45$.

At the same time, drugs that require dose adjustment in liver disorders are paclitaxel, gemcitabine, etoposide, and vinorelbine. Docetaxel is only given when there is no liver disorder. Etoposide is not recommended if the bilirubin is more than 2.5 times normal. Paclitaxel is also not recommended if the bilirubin is more than 3.5 times normal.

Cisplatin is a platinum-based chemotherapy that is often used as a single drug or in combination to treat solid tumors, including lung cancer. However, the use of cisplatin is limited by its side effect profile, particularly dose-dependent nephrotoxicity. The kidneys excrete cisplatin by glomerular filtration and tubular secretion. ${ }^{24}$ 
Table 4. Adjustment of doses of anti-cancer drugs given to lung cancer with liver and kidney disorders ${ }^{8}$

\begin{tabular}{|c|c|c|}
\hline $\begin{array}{l}\text { Medicine } \\
\text { Name }\end{array}$ & Kidney Disorders & Liver Disorder \\
\hline Cisplatin & $\begin{array}{l}\text { 1. GFR }>60 \text {, dose } 75 \mathrm{mg} / \mathrm{m} 2 \text { every } 3 \text { weeks } \\
\text { 2. GFR }<60 \text {, not recommended }\end{array}$ & --- \\
\hline Carboplatin & 3. GFR > 60, AUC5 or AUC6 doses every 3 weeks & --- \\
\hline Pemetrexed & $\begin{array}{l}\text { 1. GFR }<60 \text {, as per Calvert or Chatelut formula } \\
\text { 2. GFR } 45->60 \text {, dose } 500 \mathrm{mg} / \mathrm{m} 2 \text { every } 3 \text { weeks } \\
\text { 3. GFR }<45 \text {, not recommended }\end{array}$ & --- \\
\hline Etoposide & $\begin{array}{l}\text { 1. GFR }>60 \text {, dose } 100-120 \mathrm{mg} / \mathrm{m} 2 \text { every } 3 \text { weeks } \\
\text { 2. GFR } 15-60 \text {, dose } 75 \mathrm{mg} / \mathrm{m} 2 \text { every } 3 \text { weeks } \\
\text { 3. GFR }<15 \text { or hemodialysis, dose } 50 \mathrm{mg} / \mathrm{m} 2 \\
\text { every } 3 \text { weeks }\end{array}$ & $\begin{array}{l}\text { 1. Normal, dose } 100-120 \mathrm{mg} / \mathrm{m} 2 \text { on } \mathrm{H} 1,2,3 \\
\text { every } 3 \text { weeks } \\
\text { 2. Bilirubin }>1.25-2.5 \times \mathrm{N} \text {, dose reduced by } 50 \% \\
\text { 3. Bilirubin }>2.5 \times \mathrm{N} \text {, not recommended }\end{array}$ \\
\hline Gemsitabin & --- & $\begin{array}{l}\text { 1. Normal, dose } 1000-1250 \mathrm{mg} / \mathrm{m} 2 \\
\text { 2. AST-ALT-Bilirubin >1-3x N, dose } 800 \mathrm{mg} / \mathrm{m} 2\end{array}$ \\
\hline Paclitaxel & --- & $\begin{array}{l}\text { 1. Normal, dose } 175-200 \mathrm{mg} / \mathrm{m} 2 \text { every } 3 \text { weeks } \\
\text { 2. AST-ALT>N, dose } 135 \mathrm{mg} / \mathrm{m} 2 \text { every } 3 \text { weeks } \\
\text { 3. Bilirubin }>1.25-2 \times \mathrm{N} \text {, dose } 115 \mathrm{mg} / \mathrm{m} 2 \text { every } \\
3 \text { weeks } \\
\text { 4. Bilirubin }>2-3.5 \times \mathrm{N} \text {, dose } 100 \mathrm{mg} / \mathrm{m} 2 \text { every } 3 \\
\text { weeks } \\
\text { 5. Bilirubin }>3.5 \times \mathrm{N} \text {, not recommended }\end{array}$ \\
\hline Dosetaxel & --- & $\begin{array}{l}\text { 1. Normal, } 75 \mathrm{mg} / \mathrm{m} 2 \text { every } 3 \text { weeks } \\
\text { 2. Num }>\mathrm{N} \text {, not recommended } \\
\text { 3. AST-ALT }>1.5 x \mathrm{~N} \text {, not recommended }\end{array}$ \\
\hline Vinorelbine & --- & $\begin{array}{l}\text { 1. Normal, dose } 25-30 \mathrm{mg} / \mathrm{m} 2 \text { per week } \\
\text { 2. Bilirubin }>1.75-2.5 \times \mathrm{N} \text {, dose reduced by } 50 \% \\
\text { 3. Bilirubin }>2.5 \times \mathrm{N} \text {, dose reduced by } 75 \%\end{array}$ \\
\hline
\end{tabular}

If there has been a decline in renal function before cisplatin administration, it is recommended to use another platinumbased chemotherapy drug with less nephrotoxic effect, such as carboplatin. Renal function should be observed one week after cisplatin administration. ${ }^{25}$

Most damage occurs in the proximal tubule. This is also because cells in the proximal tubule take up cisplatin via organic cationic transporter-2 (OCT-2). The accumulation of cisplatin in the proximal tubule results in cellular damage due to oxidative stress and the production of proinflammatory cytokines. TNF-, a potent inflammatory mediator, causes apoptosis. Cisplatin also activates p53 and signaling pathways, such as mitogen-activated protein kinase, which promote cell death. ${ }^{26}$

Carboplatin has a lower nephrotoxic effect than cisplatin due to the lack of chloride ion content and lowers drug uptake via OCT-2. ${ }^{26}$ Therefore, carboplatin is said to have good pharmacokinetic and pharmacodynamic effects in CKD patients. However, most carboplatin will bind to protein after 24 hours, so hemodialysis is carried out after 24 hours. ${ }^{19}$

Pemetrexed is a methotrexate derivative and an antifolate drug that inhibits enzymes involved in purine and pyrimidine metabolism by inhibiting DNA and RNA synthesis. Pemetrexed can be used as a single drug or combined with other antineoplastic drugs such as cisplatin 
or carboplatin. Pemetrexed is excreted through the kidneys in an unchanged form. According to the FDA, for information on how to use pemetrexed, no dose adjustment is required in patients whose $\mathrm{CrCl}$ is above $45 \mathrm{~mL} / \mathrm{min} / 1.73 \mathrm{~m}^{2}$. Below this limit, administration of pemetrexed is not recommended because there is an increased risk of toxic effects. Pemetrexed can cause damage to the renal tubules, resulting in ATN. ${ }^{27}$

The risk of nephrotoxicity is higher in patients who who have previous nephrotoxic chemotherapy and in patients who have risk factors for CKD, such as diabetes and hypertension. In addition, apical folate receptors and basolateral folate carriers can carry pemetrexed to the renal tubules, causing nephrotoxicity. ${ }^{26}$ Patients with AKI may experience improvement in renal function after discontinuation of pemetrexed, although the renal function does not improve in some patients, and interstitial fibrosis develops. ${ }^{27}$

\section{CONCLUSION}

Chemotherapy with anticancer drugs is given at the maximum tolerated dose and is calculated based on the body surface area. The characteristics of anticancer drugs that have a narrow therapeutic index and large pharmacokinetic variability between individuals require special attention. Understanding the effects of pharmacokinetic changes in certain anticancer drugs is very important to determining the appropriate dose to achieve maximum efficacy and avoid toxicity. Administration of anticancer drugs must consider other factors that may affect drug pharmacokinetics, such as renal and hepatic function. Most anticancer drugs are used in combinations that are safe and effective. The goal of adjusting the dose of a particular drug for a patient who may have organ failure is to achieve a level of drug exposure similar to that of a patient with normal organ function. Therefore, benefit and risk assessments should be carried out for each patient individually.

Before giving chemotherapy, an assessment of kidney and liver function was carried out. Renal function assessment calculates the glomerular filtration rate or creatinine clearance. Assessment of liver function can be done from the Child-Pugh score or baseline bilirubin and aminotransferase enzymes in the patient. In addition, hepatitis screening was also carried out. The assessment results will determine the recommended dose of anticancer drugs given to achieve treatment goals.

\section{REFERENCES}

1. Hendrayana T, Wilmer A, Kurth V, Schmidt-Wolf IGH, Jaehde U. Anticancer Dose Adjustment for Patients with Renal and Hepatic Dysfunction: From Scientific Evidence to Clinical Application. Sci Pharm. 2017;85(1).

2. Sung $H$, Ferlay $J$, Siegel $R L$, et al. Global Cancer Statistics 2020: GLOBOCAN Estimates of Incidence 
and Mortality Worldwide for 36 Cancers in 185 Countries. CA Cancer J Clin. 2021;71(3):209-249.

3. Kementrian Kesehatan RI. Hari Kanker Sedunia 2019. Kementrian Kesehatan RI.

https://www.kemkes.go.id/article/vie w/19020100003/hari-kanker-sedunia2019.html. Published 2019.

4. Yuan M, Huang LL, Chen JH, Wu J, Xu Q. The emerging treatment landscape of targeted therapy in non-small-cell lung cancer. Signal Transduct Target Ther 2019 41. 2019;4(1):1-14.

5. Kementrian Kesehatan RI. Pedoman Nasional Pelayanan Kedokteran: Kanker Paru. Jakarta: Kementerian Kesehatan RI; 2018.

6. Krens SD, Lassche G, Jansman FGA, et al. Dose recommendations for anticancer drugs in patients with renal or hepatic impairment. Lancet Oncol. 2019;20(4):e200-e207.

7. Shahinian VB, Bahl A, Niepel D, Lorusso V. Considering renal risk while managing cancer. Cancer Manag Res. 2017;9:167-178.

8. Leduc C, Antoni D, Charloux A, Falcoz $P E$, Quoix E. Comorbidities in the management of patients with lung cancer. Eur Respir J. 2017;49(3).

9. Field KM, Dow C, Michael M. Part I: Liver function in oncology: biochemistry and beyond. Lancet Oncol. 2008;9(11):1092-1101.

10. Undevia SD, Gomez-Abuin G, Ratain MJ. Pharmacokinetic variability of anticancer agents. Nat Rev Cancer 2005 56. 2005;5(6):447-458.
11. Rauf S, Gooding JJ, Akhtar K, et al. Electrochemical approach of anticancer drugs--DNA interaction. $J$ Pharm Biomed Anal. 2005;37(2):205217.

12. Olaussen KA, Postel-Vinay $S$. Predictors of chemotherapy efficacy in non-small-cell lung cancer: a challenging landscape. Ann Oncol Off $J$ Eur Soc Med Oncol. 2016;27(11):2004-2016.

13. NCCN Clinical Practice Guideline in Oncology. Non-Small Cell Lung Cancer Version 2. NCCN Clinical Practice Guideline in Oncology; 2018.

14. McMahon BA, Rosner MH. GFR Measurement and Chemotherapy Dosing in Patients with Kidney Disease and Cancer. Kidney360. 2020;1(2):141-150.

15. Launay-Vacher V, Janus N, Deray G. Renal insufficiency and cancer treatments. ESMO Open. 2016;1(4).

16. Inker $\mathrm{LA}$, Astor $\mathrm{BC}$, Fox $\mathrm{CH}$, et al. KDOQI US commentary on the 2012 KDIGO clinical practice guideline for the evaluation and management of CKD. Am $J$ Kidney Dis. 2014;63(5):713-735.

17. Levey AS, Stevens LA, Schmid $\mathrm{CH}$, et al. A New Equation to Estimate Glomerular Filtration Rate. Ann Intern Med. 2009;150(9):604.

18. Lea-Henry TN, Carland JE, Stocker SL, Sevastos J, Roberts DM. Clinical Pharmacokinetics in Kidney Disease: Fundamental Principles. Clin J Am SoC Nephrol. 2018;13(7):1085-1095. 
19. Latcha S. Chapter 12: Pharmacokinetics of Chemotherapeutic Agents in Kidney Disease. In: Onco-Nephrology Curriculum. New York: American Society of Nephrology; 2016.

20. Talal $A H$, Venuto $C S$, Younis I. Assessment of Hepatic Impairment and Implications for Pharmacokinetics of Substance Use Treatment. Clin Pharmacol drug Dev. 2017;6(2):206212.

21. Peveling-Oberhag J, Zeuzem S, Peng Yong W, et al. Effects of Hepatic Impairment on the Pharmacokinetics of Everolimus: A Single-Dose, OpenLabel, Parallel-Group Study. Clin Ther. 2013;35(3):215-225.

22. Lim R, Holt A. Hepatitis B and C prophylaxis in patients receiving chemotherapy. Viral Hepat Pract. 2014;6(1):13.

23. Yeo W, Johnson PJ. Diagnosis, prevention and management of hepatitis $\mathrm{B}$ virus reactivation during anticancer therapy. Hepatology. 2006;43(2):209-220.

24. Miller RP, Tadagavadi RK, Ramesh G, Reeves WB. Mechanisms of Cisplatin Nephrotoxicity. Toxins (Basel). 2010;2(11):2490.

25. Ozkok A, Edelstein CL. Pathophysiology of cisplatin-induced acute kidney injury. Biomed Res Int. 2014;2014.

26. Shirali AC, Perazella MA. Tubulointerstitial injury associated with chemotherapeutic agents. $A d v$ Chronic Kidney Dis. 2014;21(1):56-63.
27. Rombolà G, Vaira $F$, Trezzi $M$, Chiappini N, Falqui V, Londrino $F$. Pemetrexed induced acute kidney injury in patients with non-small cell lung cancer: reversible and chronic renal damage. $J$ Nephrol. 2015;28(2):187-191. 